\title{
PERCEPÇÕES DE UMA PROFESSORA INICIANTE ACERCA DAS CONTRIBUIÇÕES DA PESQUISA EM SUA FORMAÇÃO INICIAL PARA O ENSINO DE MATEMÁTICA
}

Fernando Schlindwein SANTINO Universidade Estadual Paulista "Júlio de Mesquita Filho" - FCT/UNESP

Presidente Prudente, SP - Brasil

fernando.santino@unesp.br ORCID: https://orcid.org/0000-0002-7757-8826

Klinger Teodoro CIRÍACO Universidade Federal de São Carlos - UFSCar/DTPP

São Carlos - SP-Brasil

klinger.ciriaco@ufscar.br ORCID: https://orcid.org/0000-0003-1694-851X

Ana Carolina FAUSTINO Universidade Federal de Mato Grosso do Sul-UFMS/CPNV

Naviraí-MS - Brasil carolina.faustino@ufms.br ORCID: https://orcid.org/0000-0002-2059-9466

RESUMO: Compreender em que medida a pesquisa de trabalho de conclusão de curso, desenvolvida na licenciatura em Pedagogia, contribui para a prática pedagógica de uma professora que ensina Matemática, em seus primeiros anos de carreira, com base em suas percepções declaradas é o objetivo deste artigo. A investigação classifica-se como qualitativa, com análise interpretativa. A produção de dados deu-se a partir de uma entrevista semiestruturada com uma docente que atuava em uma instituição pública de ensino no interior do Estado de Mato Grosso do Sul. Os resultados evidenciaram que o TCC em Educação Matemática, mobilizou elementos relacionados a construção do início da carreira, tais como: a) mudança de atitude em relação ao conhecimento matemático; b) desenvolvimento de autonomia profissional, perante o papel da pesquisa na formação inicial, incentivando para a formação continuada; c) superação do "choque com o real" no início da docência e; d) a mudança de atitudes, dado que possibilitou uma abordagem da Matemática de forma lúdica.

PALAVRAS-CHAVE: Formação Inicial de Professores. TCC em Educação Matemática. Início da Docência. 


\title{
INSIGHTS OF A BEGINNING TEACHER ABOUT RESEARCH'S INPUTS INTO HER EARLY EDUCATION IN MATHEMATICS
}

\begin{abstract}
The objective of this article is to understand to what extent the research of the course conclusion work, developed in the Pedagogy degree, contributes to the pedagogical practice of a elementary school teacher who teaches Mathematics, in her first years of professional life, based on her stated perceptions. The research is classified as qualitative, with interpretative analysis. The data was produced from a semi-structured interview with a teacher who worked in a public school of Mato Grosso do Sul state (Brazil). The results showed that the CCP in Mathematics Education brought together elements related to the development of the beginning of the career, such as: a) change of attitude towards mathematical knowledge; b) development of professional autonomy, given the role of research in initial education, encouraging for continuing education; c) overcoming the "shock with the reality" at the beginning of teaching and; d) change of attitudes, since it enabled a ludic approach to Mathematics.
\end{abstract}

KEY WORDS: Early Professors Education. CCP in Mathematics Education. Beginning of teaching.

\section{PERCEPCIONES DE UNA PROFESORA PRINCIPIANTE SOBRE LAS CONTRIBUCIONES DE INVESTIGACIÓN EN SU FORMACIÓN INICIAL PARA LA ENSEÑANZA DE MATEMÁTICAS}

RESUMEN: El propósito de este trabajo es comprender hasta qué punto la tesis, desarrollada en la graduación en Pedagogía, contribuyó a la práctica pedagógica de una profesora que enseña matemáticas en sus primeros años de trabajo, basado en sus percepciones declaradas. La investigación se clasifica como cualitativa, con análisis interpretativo. La producción de datos se realizó a partir de una entrevista semiestructurada con una profesora que trabajaba en una institución educativa pública en el interior del estado de Mato Groso del Sur (Brasil). Los resultados mostraron que la tesis en Educación Matemática movilizó elementos que ayudaron en los primeros años de enseñanza, tales como: a) cambio de actitud hacia el conocimiento matemático; b) desarrollo de la autonomía profesional, ante el papel de la investigación en la formación inicial, alentando para la educación continua; c) superar el "choque con lo real" en los primeros años de enseñanza y; d) el cambio de actitudes, hecho que permitió un enfoque lúdico en el trabajo con las matemáticas.

PALABRAS-CLAVE: Formación inicial del profesorado. Tesis en Educación Matemática. Primeros años de enseñanza. 


\section{INTRODUÇÃO}

Descrevemos encaminhamentos e resultados de uma investigação, fruto do plano de trabalho "Identidade profissional de professores iniciantes: correlações entre a pesquisa em Educação Matemática e a constituição da prática pedagógica", vinculada ao Programa Institucional de Bolsas de Iniciação Científica da Universidade Federal de Mato Grosso do Sul - PIBIC/UFMS, Campus Naviraí, a qual obteve financiamento do Conselho Nacional de Desenvolvimento Científico e Tecnológico (CNPq) no período de agosto/2018 a julho/2019.

Na pesquisa em pauta, objetivou-se compreender em que medida o Trabalho de Conclusão de Curso (TCC), desenvolvido na licenciatura em Pedagogia, contribuiu para a construção do início da docência e prática pedagógica do professor que ensina Matemática em seus primeiros anos de carreira. Para este artigo, optamos por apresentar os dados da entrevista semiestruturada desenvolvida com uma das colaboradoras do estudo, licenciada em Pedagogia, uma vez que as informações recolhidas cumpriram o papel de caracterizar e retratar processos formativos possibilitados pelo TCC e que foram determinantes para a continuidade dos estudos pré e pós-entrada na carreira da professora iniciante.

As motivações para este estudo decorrem de dados anteriores da investigação institucional, a qual o plano de trabalho vincula-se. Referimo-nos, especificamente, ao fato de que as informações coligidas no trabalho anterior apontam evidências de possíveis contribuições que os processos de pesquisa, na modalidade de trabalho de conclusão de curso, propiciam ao professor em formação inicial. Além disso, nosso envolvimento direto em espaços de formação que buscaram articular práticas de ensino, pesquisa e extensão, os quais foram criados para a promoção de atitudes mais favoráveis frente à Matemática e seu ensino nos anos iniciais também fortalece a hipótese de que o TCC e a pesquisa na formação inicial constituem-se elemento que oportuniza aspectos da aprendizagem da docência (MIZUKAMI, 2006), justamente porque quando o licenciando se aproxima de referenciais teórico-metodológicos, este tem seu repertório didático-pedagógico ampliado, uma vez que ao tomar contato com a literatura especializada na Educação Matemática, por exemplo, passa a conhecer indicadores e proposituras de direcionamento da prática pedagógica em relação aos conteúdos matemáticos (CIRÍACO; PIROLA, 2018).

Diante do exposto, emergiu o seguinte questionamento:

Como o trabalho de conclusão de curso, desenvolvido na licenciatura em Pedagogia, contribui para a prática pedagógica de professoras que ensinam Matemática em início de carreira?

Na busca por respostas à questão, objetivamos contribuir para estudos da área na perspectiva de avançar na possibilidade de construção de práticas que visem levantar elementos características tanto de processos de pesquisa na formação de professores quanto da fase de indução à docência.

\section{Antecedentes do processo investigativo e a constituição do referencial teórico}

A partir da pesquisa modificou muito minha postura frente à Matemática. Incógnita1 .

Mudou bastante minha postura porque agora eu tenho esse entendimento, agora eu conheço mais sobre o conteúdo, então, minha postura modificou muito com a pesquisa. Aritmética.

O TCC ampliou muito minha visão em relação à Matemática, ampliou mais ainda meus conhecimentos. Simetria.

1 Nome fictício de uma das participantes da pesquisa anterior. 
Os casos descritos e analisados em planos de trabalhos anteriores em decorrência do projeto de pesquisa "Implicações da prática investigativa na mudança de atitude e crença de autoeficácia em relação à Matemática no curso de Pedagogia2", cadastrado na UFMS junto à Pró-Reitoria de Pesquisa e Pós-Graduação, revelaram a inegável contribuição do papel que o estudo no campo do ensino de Matemática, decorrente de seus TCC's, proporcionou à formação inicial de futuras professoras. As epígrafes que iniciaram a seção do referencial não nos deixam mentir.

O desenvolvimento de atitudes mais positivas frente à Matemática, a partir das leituras para a constituição de um referencial teórico de pesquisa no trabalho de conclusão de curso, bem como a aproximação da escola em atividades de observação da realidade do trabalho de professoras em exercício profissional, trouxeram reflexões que fizeram despontar em nós, mesmo antes de concluir os planos anteriores, a possibilidade de compreender em que sentido oTCC pode contribuir para a identidade de professoras iniciantes que tiveram, em seu processo formativo, um contato permeado por leituras e reflexões sistemáticas "de" e "sobre" Educação Matemática.

A Matemática tem sido apresentada no curso de Pedagogia de forma fragmentada, por essa razão a formação acaba sendo centrada em processos metodológicos de ensino, ou seja, no "como ensinar" e não no "que ensinar", isso não tem contribuído para a formação específica dos acadêmicos (CURI, 2004). Passos e Nacarato, (2018, p. 120), ao refletirem sobre a trajetória de ensino dos conteúdos matemáticos nos anos iniciais, enfatizam que "[...] há que considerar que os professores que ensinam matemática nos anos iniciais, na sua grande maioria, provêm de cursos de formação que deixam sérias lacunas conceituais para o ensino de matemática". Essa fragmentação, em consonância com as lacunas no ensino destacadas pelas autoras, aparentemente, na nossa interpretação, contribui para a criação de um ciclo vicioso, fazendo com que o docente em início de carreira continue tendo dificuldades com o conteúdo específico, o que causa consequências para com o ensino da Matemática e a consequente aprendizagem de seus alunos dos anos iniciais.

Curi e Pires (2008, p. 162) afirmam que "[...] as disciplinas relativas à matemática e seu ensino que constam das grades curriculares dos cursos de pedagogia têm uma carga horária bastante reduzida [...]", dado esse que foi possível observar através do estudo das ementas das disciplinas destinadas à Matemática em 36 instituições investigadas pelas autoras. Identificou-se que estas têm uma carga horária entre 36 e 120 horas, o que não tem contribuído para desmistificar "[...] uma concepção dominante de que o professor polivalente não precisa 'saber Matemática' e que basta saber como ensiná-la" (CURI, 2004, p. 77).

A relevância de desenvolver estudos e reflexões voltados para a formação inicial e desenvolvimento profissional dos professores no início da docência explica-se pelo fato de que as pesquisas sobre essa temática demonstram-se recentes. Embora ela tenha três décadas de estudo, somente nos últimos dez anos as práticas investigativas disseminaram em nosso país (GAMA, 2009).

Fundamentados em resultados de estudos que desenvolvemos anteriormente (SANTINO, 2018; CIRÍACO; FAUSTINO; ALMEIDA; SANTINO, 2020), é possível afirmar que conhecer mais a fundo "o que" e "como ensinar" de cada eixo investigativo, nos trabalhos de conclusão de curso das acadêmicas de Pedagogia, trouxe ainda o reconhecimento de que o futuro professor sofre influência de modelos pedagógicos dos quais participou enquanto aluno e isso pode acarretar na transposição de marcas negativas ao ensino de Matemática na escola se ele não tomar contato com a produção do conhecimento da área específica com a 
qual irá trabalhar, por isso pesquisar sobre o ensino dos conteúdos matemáticos fez com que as três futuras professoras, que abriram a seção deste referencial teórico, aumentassem a capacidade de acreditar que são capazes de ensinar seus futuros alunos, ou seja, aumentou a autoeficácia.

Segundo Ciríaco e Pirola (2018, p. 150):

[...] a autoeficácia pode ainda ser entendida como sendo uma avaliação das competências para o desempenho de uma atividade determinada dentro de um contexto específico, como é o caso da abordagem conceitual da Matemática na formação inicial de professores.

Sobre as contribuições da pesquisa para a formação inicial do professor que ensina Matemática, sem dúvida, fica claro a relevância do desenvolvimento de tal postura investigativa, as narrativas exprimem a autocrítica e a percepção da importância de rever a prática docente valorizando mais a atuação do aluno da Educação Básica no processo educativo. Pesquisar características do trabalho com este campo, durante o curso de Pedagogia, oportunizou as acadêmicas a percepção de suas limitações e a busca por modos de superação das dificuldades durante o desenvolvimento dos TCC's, esse movimento foi importante para a percepção de que o professor que ensina Matemática precisa articular sua prática em sala de aula às recomendações da literatura especializada, pois existe uma gama de possibilidades de organização das práticas com base nos princípios específicos de cada conteúdo.

Tendo em vista os vários elementos constitutivos da identidade docente e os desafios que os programas de formação inicial têm enfrentado nos últimos anos, pensamos ser preciso, então, práticas de pesquisa e estudos que acompanhem os dilemas enfrentados pelos professores iniciantes, na tentativa de encontrar meios de apoio e permanência na profissão com o objetivo de compreender com mais clareza como o professor recém-formado caminha no exercício de sua carreira e se o trabalho de conclusão de curso o auxilia neste desenvolvimento.

Torna-se necessário, assim, aproximar contextos de formação inicial que envolvam os estudantes dos cursos na realidade escolar por meio da pesquisa em educação, desde os primeiros anos da licenciatura, na intenção de amenizar os dilemas enfrentados no momento de inserção no campo profissional da docência. Acreditamos que esse significa apenas uma das formas de encarar os problemas do modelo de formação de professores, atualmente vigente no nosso país (CIRÍACO, 2016).

A entrada na carreira corresponde a uma fase decisiva e, portanto, constitutiva da identidade profissional dos professores. Para Marcelo García (1999, p. 113), “[...] os primeiros anos de ensino são especialmente importantes porque os professores devem fazer a transição de estudantes para professores e, por isso, surgem dúvidas, tensões".

Pereira (2015, p. 181), ao estudar o início da docência e as dificuldades de duas professoras em Matemática, destaca que:

O professor iniciante, ao entrar na carreira docente, está impregnado de perspectivas de mudanças e transformações na escola. O que ocorre, muitas vezes, é que ele acaba encontrando uma instituição escolar fechada, burocrática em relação às suas regras e orientações; e as perspectivas iniciais vão cedendo lugar, aos poucos, à desilusão com a realidade escolar. A entrada na carreira docente passa a constituir-se, para alguns professores, como um momento traumático. 
Em dados de trabalhos anteriores, Ciríaco (2016) constatou que, para professoras em início de carreira, uma das maiores dificuldades reside no domínio conceitual dos conteúdos matemáticos, uma vez que, segundo as colaboradoras de sua tese, a falta dos conhecimentos profissionais não Ihes garante um ambiente de aula atrativo, o que determina a desmotivação de seus alunos para a realização das atividades propostas. Contudo, em termos de pesquisa de campo, realizadas já desde o TCC, a professora iniciante pode aprimorar-se e aproximar-se da realidade de trabalho que terá de enfrentar e poderá, quando começar a lecionar, constituir atitudes mais positivas em relação à Matemática, pressuposto este que delineamos ser possível compreender com a efetivação de práticas investigativas que se busque tal correlação, dado que pressupomos ter realizado.

Nesta perspectiva, acreditamos que a pesquisa em Educação Matemática fornece uma ampliação da forma de organização do ensino, o que enriquece com o destaque importante na reflexão dos professores, seja no campo conceitual ou no metodológico da matéria de ensino.

A identidade do indivíduo como professor constrói-se por processos de constituição do seu desenvolvimento no decorrer da profissão. É preciso ter uma noção absoluta de que, o modo como nos tornamos professores ganha corpo, forma e conteúdo durante o ciclo da vida profissional, o que reforça determinadas condutas na sala de aula (CIRÍACO, 2016).

Em uma publicação sobre o ciclo de vida profissional dos professores, Huberman (1995), destaca algumas questões em relação à biografia docente, sendo elas:

Será que há "fases" ou "estágios" no ensino? Será que um grande número de professores passam pelas mesmas etapas, as mesmas crises, os mesmos acontecimentos-tipo, o mesmo termo de carreira, independente da "geração" a que pertencem, ou haverá percursos diferentes, de acordo com o momento histórico da carreira? (HUBERMAN, 1995, p. 35).

O conjunto de questões levantadas por Huberman (1995) e referenciadas aqui evidencia uma preocupação com a construção da identidade profissional dos professores ao longo do processo da carreira. Para alguns autores (DUBAR, 1997; NÓVOA, 2007) a constituição da identidade profissional parece estar atrelada à interação entre o sujeito e a sociedade, ou seja, à comunidade à qual pertence.

A construção da identidade dos professores iniciantes transita por um processo de interação entre os pares, por uma negociação de significados do trabalho docente no espaço da escola, quando eles tomam contato com profissionais mais experientes e/ou outros agentes educacionais.

Para Borba (2001, p. 34), a identidade vai muito além do processo da biografia pessoal do sujeito, uma vez que, "[...] a identidade do eu não se refere ao ser individual e absoluto, mas a uma identidade que se processa pela apropriação/negação/superação dos universos simbólicos na interação social [...]". Em relação à identidade profissional:

Podemos considerar que a construção da identidade de um professor é um processo evolutivo que se produz no decorrer da vida, está sempre inacabado, proporciona um compromisso com seus alunos e o prazer em transferir conhecimento, ou seja, demonstra o interesse em permanecer em sala de aula (ZORTÊA, 2018, p. 24).

Curi (2004) aponta que alguns professores ainda têm um sentimento de aversão à Matemática. Dessa forma, parece que no momento de transição de estudante para professor, surge algumas dificuldades em assumir 
esse papel. Uma das possibilidades para auxiliar nesse processo de transição é o caso do acadêmico (a) ter realizado a pesquisa de TCC na área de Educação Matemática, isso pode ajudar nas mudanças de crenças e atitudes em relação ao ensino, corroborando para a promoção da identidade profissional no início da carreira. Especificamente, no ensino de Matemática, algumas futuras professoras trazem consigo traumas para o ensino e aprendizagem de conteúdos matemáticos, que vem da escolaridade básica, geralmente esses sentimentos estão "naturalizados" as futuras professoras, passam a acreditar que isso faz parte da sua personalidade. "Essa naturalização e essa personalização do saber profissional são tão fortes e resultam em práticas que, muitas vezes, reproduzem os papéis e as rotinas institucionalizadas da escola" (TARDIF, 2002, p. 78).

Então, não podemos deixar que essa "naturalização" traga consequências para outros alunos, assim é necessário uma mudança, o incentivo à pesquisa na área da Educação Matemática, para que os acadêmicos de licenciatura consigam entender e "sobreviver" ao processo de iniciação profissional (HUBERMAN, 1995), sem medos e traumas da Matemática, desta forma poderemos promover a identidade profissional em consonância com a "desnaturalização" em relação ao ensino dos conteúdos da disciplina. Huberman (1995, p. 39) identifica o sentimento de sobrevivência como:

O 'choque do real' a constatação da complexidade da situação profissional: o tatear constante, a preocupação consigo próprio ('Estou a me aguentar?'), a distância entre os ideais e as realidades cotidianas da sala de aula, a fragmentação do trabalho, a dificuldade em fazer face, simultaneamente, à relação pedagógica e à transmissão de conhecimentos, a oscilação entre relações demasiadas íntimas e demasiado distantes, dificuldades com alunos que criam problemas, com material didático inadequado etc..

Nessa perspectiva, sobre o sentimento de "descoberta", "sobrevivência" e a construção da identidade, junto com ensino dos conteúdos matemáticos, encontramos estudos que apontam essas dificuldades para os professores, no início da carreira, por motivos como, por exemplo, não serem respeitados pelos colegas, pelos estudantes, falta de regras de conduta, não ter uma pessoa com quem compartilhar suas angústias e medos, frustrações, preocupações, dificuldades em dominar a sala de aula, relacionamento com os pais, cansaço físico, mental e principalmente dificuldade em saber qual conteúdo matemático ensinar, visto que "[...] compor o que ensinar de Matemática nos anos iniciais tem se mostrado um processo emblemático para o professor" (PASSOS; NACARATO, 2018, p. 130), ou seja, ao chegar à escola o docente se depara com uma realidade diferente da ideal, conhecida como "choque com a realidade" (VEENMAN, 1984). Sentimento esse decorrente das expectativas iniciais da universidade, buscando-se uma sala e estudante "ideal", com a vivência na realidade escolar em que o professor se depara com a sala e o estudante "real".

Esse "choque" pode ocorrer em relação à Matemática, por vários motivos, dentre eles: a falta do domínio dos conteúdos pelo estudante, a indisciplina em sala de aula, a falta de interesse dos alunos pela disciplina, sentimentos negativos e, inclusive, traumas da infância, problemas estes que podem geram a formação de atitudes desfavoráveis ao campo das Ciências Exatas.

No cerne do conteúdo semântico dessa análise, Ciríaco (2016, p. 167) conduz-nos a "[...] considerar que o processo de construção da identidade profissional do professor iniciante sofre implicações da interação entre ele e os demais professores, já atuantes na escola em que ingressa". Precisamos encarar a arquitetura do início da docência como um projeto coletivo da escola, demonstrando "[...] comprometimento desta instituição com esse momento específico da formação docente [...]" (ROCHA, 2006, p. 13).

Enfrentar o princípio da carreira docente como um projeto coletivo torna-se relevante na medida em que a elaboração da identidade do sujeito, de acordo com Dubar (1997), não se dá em seu nascimento, ela é 
erigida desde a infância e se reconstitui ao longo da vida em uma constante interação com o "outro". "O indivíduo nunca a constrói sozinho: ela depende tanto dos julgamentos dos outros como das suas próprias orientações e auto definições. A identidade é um produto de sucessivas socializações" (DUBAR, 1997, p. 4).

Por essa razão, a prática reflexiva da pesquisa na constituição da docência parece exercer um papel importante na identidade profissional dos professores principiantes, o que demonstra a necessidade de um estudo centrado na questão, na tentativa de compreender quais mecanismos de apoio estes se pautam para "sobreviver" a fase transitória entre o estado de estudante para o de docente.

Segundo Ciríaco (2016, p. 167), parece existir, de modo comum, aproximações entre concepções "[...] da construção da identidade do sujeito/professor, demonstrando que suas raízes estão intrinsecamente ligadas à relação entre elementos pessoais e sociais." Para o autor, a identidade profissional "[...] expressa o resultado da reprodução de papéis/modelos, descrições de ações de determinados grupos, bem como o modo de estar no ambiente daquela comunidade profissional" (CIRÍACO, 2016, p. 167).

Sendo assim, precisamos considerar a trajetória do professor durante toda sua vida pessoal e profissional, isso se quisermos compreender como a identidade se delineia/constrói. Especificamente, quando tratamos de professores iniciantes, implica reconhecer que é preciso entender as suas representações sobre a profissão e as influências da concepção durante sua vida estudantil (NEVES, 2011).

Essa questão gera a necessidade de repensarmos os modelos constituintes da prática pedagógica no início da carreira, uma vez que a identidade do principiante parece estar entrelaçada ao modo de ver e pensar o mundo do trabalho, ou seja, às suas perspectivas em relação às formas de atuação na escola, quer dizer, a sua própria formação interfere na construção de sua identidade e de sua subjetividade, ou mais ainda, no seu significado de aprender a ensinar (CIRÍACO, 2016, p. 168).

Tal dado sinaliza para a relevância de se constituir um objeto de estudo que vise caracterizar as possíveis contribuições da pesquisa para a ampliação do repertório didático-pedagógico no campo da Matemática escolar.

\section{METODOLOGIA DA INVESTIGAÇÃO}

Para a realização deste estudo, elegeu-se uma metodologia qualitativa (LÜDKE; ANDRÉ, 1986), de caráter descritivo-analítico, buscando manter um contato direto com a situação investigada, na perspectiva de "fazer ecoar" a voz da professora. Com o objetivo de compreender os significados dos relatos da entrevista, constituiu-se, assim, o elemento central da produção e análise dos dados (OSTETTO; KOLB-BERNARDES, 2015). Conforme anunciado na introdução do artigo, as informações pertinentes ao trabalho foram extraídas da pesquisa institucional3 vinculada à Pró-Reitora de Pesquisa e Pós-Graduação (PROPP/UFMS) em que o objetivo central, do estudo mais alargado, foi verificar em que medida a experiência de trabalhos de conclusão de curso, ligados à Educação Matemática, realizados por estudantes da licenciatura em Pedagogia contribuiu para mudança de atitude e crença de autoeficácia em relação à Matemática.

Para o desenvolvimento do plano de trabalho PIBIC ora exposto, realizou-se um mapeamento de egressas do curso, as quais tiveram objetos de pesquisa no campo da Educação Matemática e que durante o ano de 2018 estavam atuando em sala de aula. Na etapa do mapeamento das professoras iniciantes, por se tratar de

3 Aprovada pelo Comitê de Ética em Pesquisa da mesma instituição, inscrito sob CAAE: 60111016.6.0000.0021 na Plataforma Brasil. 
uma temática muito específica, buscamos pelas estudantes que tiveram vínculo com o "Grupo de Estudos e Pesquisas sobre Início da Docência e Ensino de Matemática" (GEPIDEM/CNPq/UFMS) e que tinham vínculo na rede municipal e/ou estadual de ensino local. Destas, localizamos nove licenciadas, sendo uma concluinte de 2014; uma de 2015; cinco de 2016 e duas do ano de 2017. No contato direto com o grupo de egressas, apenas três estavam com contrato de trabalho vigente, ou seja, eram professoras iniciantes.

Dada a natureza do processo de pesquisa empreendido, por se tratar de um estudo de iniciação científica e do espaço-tempo da produção dos dados, entendemos que não seria possível acompanhar de modo satisfatório a prática pedagógica das três professoras em início de carreira na perspectiva de compreender como o TCC forneceu elementos para constituírem suas ações com as crianças nas aulas de Matemática, razão pela qual optamos por entrevistá-las e trabalhar com uma análise das práticas declaradas, ou seja, intencionamos em seus relatos dar visibilidade aos significados que atribuíram à experiência da pesquisa na formação inicial para suas aula quando do momento de início da docência.

Primeiramente, realizamos uma entrevista piloto com uma professora e, posteriormente, as demais também foram entrevistadas. Dentre elas, encontramos a professora iniciante cujos relatos são objeto de discussão e análise neste artigo: Helena4. O critério estabelecido para o tratamento dos dados produzidos na interação pesquisador-entrevistadas levou em consideração as respostas mais elucidativas de como o trabalho de conclusão de curso, desenvolvido na licenciatura em Pedagogia, contribui para a prática pedagógica, o que se fez de modo mais consistente nos dados da entrevista com Helena.

Em respeito aos aspectos éticos, para nos referirmos à docente, utilizaremos pseudônimo que foi escoIhido pela mesma após o aceite em participar de forma voluntária, com base na assinatura do "Termo de Consentimento Livre e Esclarecido" (TCLE). Com a autorização, utilizamos como instrumentos de produção de dados a gravação em áudio-descrição da entrevista semiestruturada (MANZINI, 2004) desenvolvida.

As entrevistas e o roteiro das questões foram elaborados pensando em como as aproximações, por meio da apropriação de leituras de referenciais teórico-metodológicos, realizadas no TCC, provenientes da literatura da área de Educação Matemática contribuiu para a constituição da prática pedagógica na fase de indução à docência de Helena. Na entrevista/narrativa tentamos, pela natureza das questões propostas, desvelar condicionantes e racionalidades emergentes da investigação do trabalho de conclusão de curso. Destacamos que muito embora esta professora tivesse o título de mestre quando fora entrevistada, compreendemos que tal formação não impossibilita de perceber as influências do TCC em sua prática pedagógica declarada, isso porque como verificaremos mais adiante, a pesquisa em sua formação inicial foi motivação para querer lecionar Matemática nos anos iniciais e dar prosseguimento na pós-graduação stricto sensu.

As perguntas que compuseram o rol de questões fizeram menção à dados de caracterização (nome, ano de formação, tempo de carreira, enquadramento funcional, etc.), aprendizagens com a pesquisa na licenciatura, relação com a Matemática, ingresso na docência, dificuldades e modos de superação, bem como possíveis contribuições da pesquisa realizada na graduação para a forma como se lida e organiza o ensino.

\section{Caracterização da professora entrevistada}

Helena, com 30 anos de idade, é formada em Pedagogia, possui mestrado em Ensino e Processos Formativos pela Universidade Estadual Paulista "Júlio de Mesquita Filho" (FEIS/UNESP) em Ilha Solteira - SP. Graduou-se

4 Nome fictício. 
na Universidade Federal de Mato Grosso do Sul, Campus Naviraí - MS - em abril de 2016. Em seu trabalho de conclusão de curso, realizou um estudo com professoras iniciantes acerca de suas dificuldades com a Matemática e seu ensino durante os primeiros anos de carreira. Para este fim, teve como objetivo compreender dificuldades encontradas nos anos iniciais da docência em relação ao ensino de Matemática por professoras com formação em Pedagogia. Para atingi-lo, recorreu a uma produção de dados pautada em desenvolvimento de roteiros de entrevistas semiestruturadas com duas docentes atuantes na rede municipal de educação de Naviraí/MS em 2015. As questões que compuseram este cenário de perguntas buscaram identificar: ingresso na carreira; acolhida na escola; dificuldades com os conteúdos matemáticos e formas de superação.

Na organização escrita de seu trabalho, é possível listar uma divisão em 7 (sete) tópicos: 1) Introdução; 2) Formação de professores e ingresso a carreira: algumas características e problemas; 3) A formação matemática presente no curso de Pedagogia; 4) Delineamento metodológico; 4.1) Características das professoras iniciantes; 5) Características da formação matemática das professoras iniciantes; 6) Problemas e perspectivas do começo de carreira nas aulas de Matemática; e 7) Considerações finais.

Em agosto de 2017, foi chamada para assumir o concurso público e começou a trabalhar em setembro do mesmo ano na rede municipal local. Quando do momento da entrevista, Helena tinha experiência de 1 (um) ano e 6 (seis) meses na carreira docente. Em 2018, a professora lecionava no berçário II, no período matutino, e no período vespertino atuava em uma turma de segundo ano do Ensino Fundamental em uma escola estadual.

Com base nas experiências da trajetória e relação de Helena com a Educação Matemática, desde a infância, conseguimos retratar vivências que ora a distancia, ora a aproxima deste campo do conhecimento. Suas narrativas, expostas nos próximos itens de discussão, ilustram e exemplificam o percurso de constituição da identidade profissional e sua prática pedagógica declarada em entrevista.

A partir da constatação da existência de vivências na formação inicial com a Matemática, declarada pela docente, a análise de dados que se fará a seguir fora organizada e tratada de modo que cumpre um papel de caracterizar os episódios significativos afirmados pela entrevistada como sendo relevantes ao modo como se desenvolve profissionalmente no início da docência.

\section{"Ela ficava batendo na carteira quando as crianças não sabiam algo de Matemática": a relação de Helena com a Matemática na Educação Básica}

O título que abre espaço à discussão posta neste tópico representa uma das falas ditas por Helena. Nesta seção iremos analisar este e outros trechos da entrevista concedida pela docente. A análise dos dados da entrevista traz evidências de que as aulas de Matemática da Universidade junto com a pesquisa do TCC na área da Educação Matemática contribuíram para a entrevistada mudar as suas atitudes, bem como para que ela desenvolvesse práticas pedagógicas que favoreciam o ensino e aprendizagem matemática.

A partir da entrevista realizada, pudemos observar um pouco da sua experiência enquanto estudante da Educação Básica:

[...] minhas experiências não foram boas! Lembro-me com muito medo das aulas. Eu lembro que eu tinha uma professora muito brava e ela tinha uma régua, uma régua enorme, e ela ficava batendo na carteira quando as crianças não sabiam algo de Matemática (Helena). 
Neste trecho, podemos perceber que o contato da professora com a Matemática não foi agradável e que suas primeiras experiências sinalizam, pelo exposto, para não positivas. O processo de ensino e aprendizagem era baseado em uma perspectiva tradicional. Portanto, as vivências de Helena, enquanto estudante da Educação Básica, propiciaram o desenvolvimento de uma atitude negativa em relação à Matemática. De acordo com Sander (2014, p. 24):

De alguma forma, as atitudes são aprendidas. Pode ser de forma intencional, na qual o indivíduo pode aprender a se comportar de modo favorável ou desfavorável em relação ao objeto da atitude; ou de forma não intencional, sem que o indivíduo tenha consciência dessa aprendizagem, sem reconhecer as bases emocionais ou informacionais de suas atitudes e sem saber como ou quando aprenderam essas atitudes sustentadas.

Portanto, percebemos que a atitude pode ser incorporada de forma não intencional, podendo ser positiva ou negativa em relação ao objeto, que no caso específico deste estudo é à Matemática. Assim, " [...] a atitude (...) soluciona problemas e integra as ideias lidas com experiências prévias, de forma que novas intuições, atitudes racionais e melhores padrões de pensamento e de atividade são adquiridos" (SILVA, 1981, p. 20).

Tomando como base a fala da professora, podemos perceber que suas atitudes foram apreendidas, visto que, na sua formação na Educação Básica as suas atitudes em relação à Matemática foram negativas, porém, isso não quer dizer que precisam se perpetuar por toda a vida. Assim, destacamos a importância de uma formação inicial de qualidade que contribua para essa mudança.

Nessa perspectiva, podemos dizer que "[...] as atitudes não são inatas. Elas podem variar ao longo da vida de acordo com as experiências vividas pelo sujeito e da cultura no qual está inserido e, principalmente, as atitudes podem ser ensinadas" (SANDER, 2014, p. 26). Assim inferimos que, um dentre tantos, objetivos dos cursos de licenciatura, deveria ser a capacidade dos professores universitários de propor cenários de investigação que contribuam para que os estudantes desenvolvam atitudes positivas em relação à Matemática.

Quando questionamos sobre em que medida as suas leituras de TCC contribuíram para que ela não ensine os seus estudantes da mesma forma que aprendeu, a professora se mostrou firme e segura na resposta, e até deu exemplos de sua experiência enquanto docente no início de carreira, destacando as contribuições:

Contribuíram no sentido de que eu não trabalharia da forma que elas trabalham [referindo-se as demais docentes da escola em que hoje atua], não faria abordagem matemática da forma que elas fazem, porque eu já vi professora castigando aluno, dando conta de Matemática [destacando exercícios de fixação como "castigo"], aquilo lá quase parou meu coração. E eles [os alunos] vão ficar traumatizados para sempre com isso. [...] Você tem que buscar formas do aluno se envolver com atividade Matemática e não buscar a forma que ele se traumatize com a Matemática. A pesquisa do TCC vejo que me "abriu os olhos", estudar e discutir práticas de ensino, as dificuldades das professoras me ajudou a pensar o que quero para meus alunos: reviver o que tive quando fui aluna ou ter novas possibilidades? A decisão é minha, tenho elementos hoje para isso (Helena).

Podemos inferir, por meio dos dados apresentados, que oTCC colaborou com a mudança de visão em relação à abordagem dos conteúdos, isso porque as primeiras experiências de Helena com a Matemática, enquanto estudante da Educação Básica, foram negativas. Porém, durante a formação inicial no curso de licenciatura em Pedagogia ao optar por desenvolver uma proposta de investigação na área, a docente teve a possibilidade de ressignificar suas crenças e compreender que a Matemática deve ser ensinada com o envolvimento do estudante, para evitar traumatizá-lo. 


\section{Relação de Helena com a Matemática no Ensino Superior}

Helena, em alguns momentos, menciona também a importância da formação inicial para o aprimoramento de suas ações. Enfatiza que nas aulas de Matemática, existem vários caminhos para chegar ao resultado final de uma resolução de problemas, por exemplo.

O meu TCC contribuiu no sentido de que eu sabia que eu ia encontrar dificuldade para ensinar matemática, e eu sabia que eu iria ter todos aqueles sentimentos, e eu sabia que mesmo tendo todo sentimento, que o Huberman fala, eu não poderia me deixar levar, eu tinha que ser uma professora que pesquisasse aquela prática, de como eu iria passar para os meus alunos, opa... não deu certo? Eu fiz de um jeito você fez de outro? Então, vamos lá, vamos explicar para toda a sala, como que eu fiz, e como que você fez, para eles verem qual que é mais fácil (Helena).

Percebemos que ao se preparar, antes mesmo de estar em sala de aula, a professora demonstra que as leituras, decorrentes do trabalho de TCC, contribuíram, sobremaneira, uma vez que, ao se estudar o início da atividade profissional e as dificuldades de professoras em Educação Matemática, esta já sabia, em tese, dos problemas que poderia vir a enfrentar no início da carreira docente, dado que demonstra que a professora teve a oportunidade de se preparar física e psicologicamente, podendo assim elaborar suas próprias estratégias para ensinar Matemática, refletindo sobre as dificuldades e se preparando para lidar com elas, antes mesmo de entrar em sala de aula.

No relato, a professora também menciona os sentimentos, citados por Huberman (1995) como, por exemplo, choque de realidade, sobrevivência e as descobertas. O "choque de realidade" é expresso em relação aos problemas que o docente irá enfrentar no início de carreira. Por exemplo, durante a sua graduação o estudante, muitas vezes, espera ensinar os conteúdos para um estudante ideal, que fica em silêncio, aprende na primeira explicação, porém, ao iniciar a docência na escola ele se depara com o estudante real, às vezes, com dificuldade na aprendizagem, indisciplina em sala de aula, dentre outros. A "sobrevivência" é o momento em que o professor passa por um equilíbrio com aprendizagens constantes, para depois realmente ter o sentimento de "descoberta" onde o professor-aluno toma para si o comprometimento definitivo tendo mais confiança em sua prática (VEENMAN, 1984; HUBERMAN, 1995).

No momento em que a professora cita que chamou os estudantes que conseguiram resolver o problema de forma diferente para demonstrar para os colegas a metodologia que utilizaram, ela está contribuindo para que estes compartilhem e percebam que existem diferentes caminhos para se chegar ao resultado em uma solução de problema. Desta forma, a professora iniciante cria oportunidade para os estudantes escolherem a estratégia que acreditam ser a mais adequada para cada contexto. Na nossa interpretação, está valorizando os diferentes tipos de saberes e explicando que as crianças conseguem chegar ao mesmo resultado que ela por outros caminhos e que não, necessariamente, devem seguir um modelo pronto.

Assim, Helena se refere aos conceitos abordados por Huberman (1995) para abordar os desafios que o docente enfrenta em seu início de carreira e explicita ter se apropriado dos estudos, tanto para o ensino de conteúdos matemáticos quanto para criar a identidade docente e não desistir da carreira. Com base em tais evidências, é possível observar que prática investigativa do professor é um elemento fundamental ao seu desenvolvimento profissional e que a pesquisa, na formação inicial, apresenta-se como fator contributivo para tal.

A professora afirma ainda que a pesquisa de TCC contribuiu para sanar as necessidades formativas e, principalmente, com a sua formação enquanto alguém que inicia a carreira. O trabalho de conclusão de curso 
é citado como o grande responsável por ajudar na sua prática docente, no sentido de que devido às experiências com a Matemática, durante a investigação, ela não negligencia os direitos de aprendizagens de seus alunos, ou seja, afirma não "pular" conteúdos matemáticos pelo fato de talvez apresentar dificuldades, igual algumas de suas colegas de trabalho. Exprime a consciência de que é um direito do estudante aprender cada um dos conteúdos matemáticos e estes precisam ser apreendidos para a continuidade dos estudos na escola e, principalmente, para a vida como é o caso da "Geometria" e sua abordagem a partir de materiais manipuláveis.

Acredito, porque quando você está estudando Matemática, a Educação Matemática, você se interessa por ler aquilo, e talvez se eu não tivesse feito oTCC nessa área, e não tivesse estudado isso, eu iria pular conteúdos, coisa que eu acho um sacrilégio para as crianças, pular conteúdos, porque ela precisa aprender aquilo, e se eu não tivesse feito TCC na área, de Educação Matemática, eu acho que a primeira dificuldade que eu teria, seria a mesma dos professores da minha pesquisa de TCC, principalmente em geometria, e no uso do material concreto. Então, seria o que eu teria pulado, mas como eu verifiquei que elas tiveram essa dificuldade, senti que eu tinha a mesma dificuldade, e talvez eu poderia ter a dificuldade que elas tiveram, em trabalhar simetria, trabalhar os materiais concretos, não é? Então, tentei, busquei para que a minha pesquisa [...] fosse para estudar isso, para sanar as necessidades formativas das professoras que estão em sala de aula, e contribuiu com a minha formação também (Helena).

Nessa perspectiva, por meio da narrativa de Helena, é possível verificar a importância de se pesquisar na área da Educação Matemática desenvolvimento de autonomia profissional, perante o papel da pesquisa na formação inicial, incentivando para a formação continuada, dentre outras contribuições, para que os alunos não saiam "prejudicados" no processo de aprendizagem.

\section{A relação e abordagem da Matemática em sala de aula com o ingresso na profissão}

Ao dar continuidade na entrevista, a professora iniciante retoma seu trabalho de conclusão de curso ao citar que alguns professores não tinham a formação inicial consistente para lecionar Matemática, dado frequente nos resultados de sua pesquisa. Ao perguntar se ela tinha essas dificuldades e como as superava, comentou que se apoia nas aulas da graduação, especificamente do professor que ministrou disciplinas de "Fundamentos e Metodologias do Ensino de Matemática I" e "Fundamentos e Metodologias do Ensino de Matemática II", e não nas aulas tradicionais que teve enquanto estudante da Educação Básica.

[...] (professor Klinger) quando foi meu professor "mandou" fazer planos de aulas, desenvolver em sala de aula, então, a minha dificuldade quando eu encontro, eu tento suprir lembrando dele, diferente dos professores da minha pesquisa do TCC que se apoiam nos professores lá do Ensino Médio (e) nas séries iniciais (Helena).

Destacamos que a disciplina de "Fundamentos e Metodologias do Ensino de Matemática I e II", bem como a pesquisa de TCC, foram essenciais para os acadêmicos conectarem a teoria com a prática. Desenvolver e executar planos de aulas em consonância com o contato com o referencial teórico da área de Educação Matemática proporcionou, experiências e aproximações com a temática, que ao mesmo tempo colaboram para a ampliação do repertório didático-pedagógico dos futuros professores. Esse trecho da entrevista evidencia que Helena tem a sua base nos aprendizados do Ensino Superior enquanto a maior parte dos professores se apoiam nas experiências de quando eram estudantes dos anos iniciais e do Ensino Médio, o que na maior parte das vezes são experiências negativas que podem ser reproduzidas com seus estudantes. 
Durante a entrevista percebemos que a professora menciona a importância de fazer diferente em relação a algumas colegas de trabalho, no sentido de ensinar conteúdos matemáticos de forma lúdica para que realmente tivesse significado para as crianças, evitando aulas tradicionais.

É a questão da assimilação de cor com sólidos, que eu procuro mesmo na creche, mesmo as crianças de 2 anos [...] fiz um cartaz para eles irem colocando, montando ali o triângulo, o retângulo de formas diferentes, não na mesma posição, não da mesma cor. Então, isso é uma coisa que eu trabalhei com eles, que eu acho que a leitura que eu tive, no TCC para fazer o TCC contribuiu, noções de lateralidade, quando você vai cantar uma musiquinha. [...] Então, tudo isso, quando eu estou fazendo [...] eu estou trabalhando a Matemática, não é? Ou quando eu pego uma pecinha lá que ela não encaixa em qualquer lugar, é lá tem um carrinho e ele tem várias pecinhas de encaixar. Então, aquela criança ela vai precisar resolver aquele problema, de que ela precisa ir lá encaixar a pecinha igual, no local igual, eu tenho essa visão dos brinquedos das coisas que eu faço na creche, e que eu não teria se eu não tivesse tido as leituras que eu tive no TCC (Helena).

Helena ressalta a importância do ensino das propriedades matemáticas desde a mais tenra idade, o que vai ao encontro de pesquisas na área da Educação Matemática (CIRÍACO; ZENERATI, 2015) da Base Nacional Comum Curricular (BRASIL, 2017) e dos Parâmetros Curriculares Nacionais (BRASIL, 1997) que enfatizam a importância do desenvolvimento do pensamento matemático desde o início da escolarização. A Matemática deve ser ensinada desde a infância, isso ainda é algo desafiador, por isso devemos trabalhar e desenvolver o conhecimento lógico-matemático da criança, sempre buscando desenvolver as atividades de forma diferente.

Questionamos sobre a maneira como aborda os conteúdos matemáticos, ao passo que comentou ter realizado um trabalho interdisciplinar, nas disciplinas Ciências e Matemática, chamado "a medida da baleia", ilustrando assim sua forma de atuação profissional na Educação Infantil, pós-formação inicial:

O que a baleia é? A baleia é um mamífero, quantos quilos a baleia pesa? O tamanho da baleia? A baleia é o maior mamífero? Ela mede 32 metros, quanto dá 32 metros. Então, vamos medir 32 metros, para ver quanto é que dá, aí você vai lá com o barbante, medindo, medindo, vai medindo, vai medindo, para a criança ter uma noção do tamanho da baleia, não é? Então, isso seria um exemplo (Helena).

Já na creche, o ensino de Matemática é realizado da seguinte forma: "E aí, na creche foi o que eu te falei, não é? Das brincadeiras, dos blocos lógicos, tem peças de encaixe, tem a classificação. Então, tudo isso eu trabalho lá" (Helena). Nessa visão, percebemos a importância do trabalho realizado pela professora no momento de ensinar os conteúdos matemáticos, tanto no Ensino Fundamental quanto na Educação Infantil, além dela trabalhar com a interdisciplinaridade pede para que as crianças realizem a medida, para terem noção da medida de 32 metros como citado, além disso trabalha com o desenvolvimento da classificação por atributos de "semelhança/diferença" presentes nas formas em blocos lógicos, desde os primeiros anos de vida.

Também destacou que considera a realidade da criança na aula de Matemática:

Para abordar Matemática eu uso meios lúdicos, histórias, direcionamentos de lateralidade por meio da oralidade... Quando você fala: "Fulana [em alusão ao nome de alguma criança, por exemplo] pega o papel que está em cima do armário", "joga o papel dentro do lixo" [...], aqui temos noções de ordem espacial. Tem ainda uma história lá [a creche] que eu conto e vou indagando as crianças com questões de lateralidade: "por cima não dá?", "por baixo não dá?", "para direita não dá?", 
"pela esquerda não dá?". Nestes momentos de interação, sempre me coloco como um espelho das crianças [...] eu sento na frente, então, a minha direita é a esquerda deles, então quando eu falar minha esquerda é a minha direita, aí falo em cima não dá... embaixo não dá... Então, eu estou sempre buscando esses meios para trabalhar matemática, na realidade em que estou (Helena).

Nesse sentido, destacamos a importância de utilizar procedimentos didáticos que incorporem aspectos da ludicidade nas vivências com as crianças, conforme os pressupostos de Smole (1996, p. 138):

[...] o jogo serve como meio de exploração e invenção, reduz a conseqüência os erros e dos fracassos da criança, permitindo que ela desenvolva sua iniciativa, sua autoconfiança, sua autonomia. No fundo, o jogo é uma atividade séria que não tem conseqüência frustrante para a criança.

Além da potencialidade do jogo na Educação Infantil, também está presente na fala da professora a importância de se colocar no lugar da criança para fazer intervenções adequadas. Assim, destacamos o papel da alteridade, ou seja, ter a capacidade de se colocar no lugar do outro, neste caso, fisicamente, saber que o lado direito das crianças será espelhado e ela deverá mostrar o braço esquerdo. Ao especificar a realidade com o ensino de Geometria, Helena relata:

Essa noção de dentro e fora, maior, menor, por exemplo, seu chinelo é maior do que o de quem? Você consegue trabalhar classificação com eles, no começo do ano eles não conhecem nada, depois eles vão conhecendo, outro exemplo: "a sua bolsa é essa, a minha é esta". Qual bolsa é maior? Então, tudo isso...é tão bonitinho, eles são umas gracinhas.

A abordagem utilizada na Educação Infantil por esta docente se afasta de uma abordagem tradicional da Matemática que acaba por antecipar a escolarização através da reprodução de atividades mecânicas. Helena busca trabalhar a partir de jogos, brincadeiras e da literatura infantil. Tal forma de constituir o repertório didático de sua atividade pedagógica foi sendo construída a partir de seu contato positivo com a Matemática e a literatura em Educação Matemática durante a formação inicial em Pedagogia a partir do trabalho de conclusão de curso, dado muito recorrente em vários momentos da entrevista concedida.

Frente as declarações postas em apreciação nos relatos de Helena, podemos inferir que, ao tratarmos de "Matemática tradicional", neste estudo nos baseamos no conceito de Ole Skovsmose que relaciona esse tipo de ensino ao absolutismo burocrático, ou seja, quando o docente encontra um erro e, utilizando de sua autoridade pede para que o estudante corrija, mas sem explicar o real motivo do erro, apenas diz se está certo ou errado. Além de utilizar apenas a Matemática com referência à Matemática e somente a ela, o que não proporciona nenhum significado para o estudante, o professor não oportuniza um cenário de investigação para os mesmos (ALRØ; SKOVSMOSE, 2016). Outrossim, Skovsmose (2014, p. 16):

Exercícios desempenham um papel crucial no ensino de matemática tradicional. Ao longo de todo o período em que frequentam a escola, as crianças, em sua maioria, respondem a mais de 10 mil exercícios. Contudo, essa prática não ajuda necessariamente a desenvolver a criatividade matemática. Será que o papel da educação matemática é preservar visões equivocadas de ordem social e política que estão profundamente arraigadas na sociedade.

Portanto, é de suma importância o papel do docente para promover um olhar crítico para que os estudantes, por meio da Matemática, possam enxergar essas visões equivocadas tanto da ordem social quanto da ordem política que estão presentes no seu cotidiano. O trabalho do professor será para que não aconteça a ideologia da certeza em sala de aula, visto que a "ideologia da certeza" implica: 
[...] ver a Matemática como um sistema perfeito, infalível, não influenciado por qualquer interesse político, social ou ideológico. Também faz parte da ideologia da certeza considerar que uma solução matematizada de um problema é sempre superior às soluções não matematizadas. Esta é a visão hegemônica, não apenas no senso comum, mas também nas discussões acadêmicas e científicas. Eles atribuem a construção de tal ideologia à educação acrítica, reforçada por atividades escolares com uma única solução, problemas com dados inventados que não são reais, e pseudo-aplicações da Matemática na realidade. Essa ideologia promove a Matemática pelo seu enorme poder de aplicação, porém não incita a discussão acerca das hipóteses, ou dos modelos alternativos e das soluções diferentes (BORBA, 2001, p. 63, destaque nosso).

Nessa ótica, para começar a "caminhar" em prol da desconstrução do processo da ideologia da certeza, é importante que os professores propiciem aulas diferenciadas como, por exemplo, cenários investigativos em que os estudantes criem problemas abertos com mais de uma resolução, problemas sem solução, problemas com falta de dados, dentre outros.

Esse aspecto de considerar os diferentes tipos de caminhos e respostas, encontradas pelos estudantes, são valorizadas na fala da professora entrevistada: "[...] opa... não deu certo? Eu fiz de um jeito você fez de outro? Então, vamos lá, vamos explicar para toda a sala, como que eu fiz, e como que você fez, para eles verem qual que é mais fácil" (Helena). Podemos perceber que a docente vai contra a "ideologia da certeza" e, desta forma, possibilita que os estudantes participem ativamente na construção de diferentes formas para chegar ao resultado.

Além disso, ela ainda enfatizou a importância de escutar ativamente as diferentes estratégias apresentadas pelos estudantes.

Durante a entrevista a professora cita uma das dificuldades que encontraria no, início de carreira, caso não tivesse realizado a pesquisa na área da Educação Matemática: "[...] eu acho que a primeira dificuldade que eu teria, seria a mesma dos professores da minha pesquisa de TCC, principalmente em geometria, e no uso do material concreto" (Helena). Em relação ao uso do material manipulável e a capacidade de abstração, analisando o que apontam as autoras Nacarato e Passos (2003, p. 78):

A visualização pode ser considerada como a habilidade de pensar, em termos de imagens mentais (representação mental de um objeto ou de uma expressão), naquilo que não está ante os olhos, no momento da ação do sujeito sobre o objeto. O significado léxico atribuído à visualização é o de transformar conceitos abstratos em imagens reais ou mentalmente visíveis.

Ao analisar os estudos das referidas autoras, observamos a importância do material manipulável para que as crianças possam visualizar e, assim evoluir da fase em que tem que observar o material físico para um pensamento abstrato, desta forma percebemos o quão importante é pesquisar referenciais teóricos na área da Educação Matemática contribuindo para a formação de professores e de estudantes.

A partir do que a professora iniciante apontou, foi possível perceber a forma em que aborda os conteúdos matemáticos. Demonstra a importância do lúdico em consonância com o ensino da Matemática, ou seja, todas as atividades lúdicas têm um objetivo, não são apenas brincar por brincar, as interações e brincadeiras constituem-se eixo catalisador das aprendizagens infantis em sua prática.

Pelas declarações da entrevista, fica claro o quão é relevante o diálogo nas aulas. 
[...] nas aulas de matemática dos anos iniciais, o diálogo consiste no compartilhamento de diferentes visões em relação ao objeto a ser estudado. Tal objeto pode constituir-se de um problema matemático, da interpretação ou construção de um gráfico, dos procedimentos algoritmos, de jogos, da investigação matemática, entre outros. O diálogo se concretiza como possibilidade de compreender qual a visão de mundo que outro ser humano tem sobre o objeto matemático (FAUSTINO, 2018, p. 14).

O diálogo possibilita que os estudantes compartilhem as diferentes possibilidades de resolução de uma mesma tarefa e negociem significados matemáticos. Para tanto, é essencial que o professor crie momentos propícios de socialização das diferentes estratégias e escute ativamente os estudantes. Articulada ao diálogo, podemos apontar a importância da ludicidade na Educação Infantil, pois é por meio dos brinquedos e brincadeira que as crianças conseguem aprender/conectar os conteúdos na teoria com a prática tanto conteúdos da língua materna como também conteúdos matemáticos, como afirma Kishimoto (1994, p. 111) "[...] a imagem de infância é enriquecida, também, com o auxílio de concepções psicológicas e pedagógicas, que reconhecem o papel do brinquedo, da brincadeira, como fator que contribui para o desenvolvimento e para a construção do conhecimento infantil".

Diante dos dados produzidos e apresentados até aqui, cumpre salientar que, na condição de professores que ensinam Matemática, podemos recorrer aos referencias teóricos para irmos aos poucos repensando a metodologia de ensino, isso para que as crianças possam ter a aprendizagem junto com as atividades lúdicas que desenvolvam elas de forma integral.

Frente aos resultados desta pesquisa, fica claro que Helena parece, ao que tudo indica, ter mudado sua atitude e a percepção devido ao trabalho de TCC na área da Educação Matemática. Assim, podemos dizer que o desenvolvimento da pesquisa na formação inicial em Pedagogia influenciará a forma em que o professor aborda os conteúdos matemáticos em sala de aula e que esta constitui-se uma alternativa e iniciativa interessante à formação do professor que ensinará Matemática. Seguindo tal compreensão, defendemos o posicionamento de que, mesmo os estudos apontando que quem opta pela licenciatura em Pedagogia quer "fugir" da Matemática e que talvez apenas com o curso em si não garanta a efetivação de uma atitude positiva, o incentivo à investigação "de" e "sobre" a Educação Matemática, seja em estudos da formação docente, seja do processo de ensino e aprendizagem, torna-se, na nossa intepretação, pressuposto basilar para se criar oportunidades de desenvolvimento de interesse pela área (CIRÍACO; PIROLA, 2018).

\section{Considerações finais: o que a experiência de Helena nos ensina?}

Os relatos descritos e analisados neste estudo evidenciam a importância da pesquisa em Educação Matemática no curso de licenciatura em Pedagogia de uma universidade pública, revelando a potencialidade de refletir sobre o ensino e o trabalho pedagógico, por meio da pesquisa de TCC. Os resultados deste estudo indicam que o contato com referenciais teóricos da área da Educação Matemática, contribuiu para a constituição da identidade docente em consonância com a ampliação do repertório didático-pedagógico de uma professora que ensina Matemática nos anos iniciais de sua docência, tanto para a Educação Infantil quanto para o Ensino Fundamental.

Os dados presentes na entrevista trazem evidências de que as experiências positivas que a professora teve enquanto acadêmica da licenciatura em Pedagogia foram mais fortes do que as experiências negativas enquanto estudante da Educação Básica. Identificamos a importância da pesquisa, na área da Educação Matemática, para aqueles que têm facilidade com a Matemática, porém, o estudo nessa área é de suma importância, 
principalmente, para os acadêmicos que apresentam aversão/traumas (dificuldades) com experiências negativas, isso porque, dada a experiência que temos vivenciado atuando diretamente com a formação inicial de professores, com a aproximação de leituras da literatura especializada na temática, os futuros docentes têm a oportunidade de conhecer mais a fundo o campo e oportunidades são criadas para se desenvolver experiências positivas em relação à Matemática. Constatamos ainda que esse contato com os referencias teóricos da Educação Matemática, durante o desenvolvimento do TCC e as aulas de Fundamentos e Metodologias do Ensino de Matemática, auxiliaram para superar a perspectiva de que a Matemática é difícil e só alguns conseguem "dominar", que existe uma única forma de resolver os exercícios, entre outros.

A contribuição de Helena, via entrevista semiestruturada, possibilitou caracterizarmos, de forma mais detalhada, a potencialidade da investigação na formação de professores que ensinam Matemática, o que trouxe o entendimento de que as suas experiências vivenciadas no curso de Pedagogia foram elementos primordiais à constituição de sua prática entre a pesquisa na formação inicial e a sala de aula, agora como professora iniciante.

Geralmente, os cursos de Pedagogia têm uma ou duas disciplinas pertencentes ao trabalho com a Matemática, porém com o desenvolvimento do TCC foi possível modificar a forma de enxergar a Matemática, ou seja, a professora mudou a perspectiva e, com isso, consegui encontrar alternativas para seguir com estudos e se desenvolver profissionalmente na área (cursou mestrado e demonstrou ter práticas que se afastam da Matemática tradicional).

Em relação ao trabalho da pesquisa institucional, a qual engloba parte do processo da investigação aqui relatada, a aproximação com o contexto deste estudo contribuiu para que pudéssemos perceber o papel dos grupos de pesquisas na formação inicial, bem como que a presença da Educação Matemática, seja pelo TCC ou pelas práticas formativas das disciplinas obrigatórias do curso de Pedagogia, representam eixos catalizadores de aprendizagens pré-profissionais que contribuíram para o início da docência, seja para a mudança de atitudes em relação à Matemática ou para à utilização dos meios lúdicos para promoção de uma aprendizagem significativa para os estudantes da Educação Básica. 


\section{REFERÊNCIAS}

ALRØ, H; SKOVSMOSE, O. Diálogo e aprendizagem em Educação Matemática. Trad. Orlando de A. Figueiredo. Belo Horizonte: Autêntica, 2006.

BORBA, A. M. Identidade em construção: investigando professores na prática da avaliação escolar. São Paulo: EDUC; Santa Catarina: Univali, 2001.

BORBA, M. C. A ideologia da certeza em Educação Matemática. In: Ole Skovsmose. (Org.). Educação Matemática Crítica: a questão da Democracia. 1ed.Campinas: Papirus, 2001, v. 1, p. 127-148.

BRASIL, Ministério da Educação. Base Nacional Comum Curricular. Brasília. 2017. Disponível em: http:// basenacionalcomum.mec.gov.br/abase/\#infantil/os-objetivos-de-aprendizagem-e-desenvolvimento-para-a-educacao-infantil. Acesso em: 12, maio 2019.

, MEC/SEF. Ministério da Educação e do Desporto - Secretaria de Ensino Fundamental. Parâmetros Curriculares Nacionais: Matemática / Secretaria da Educação Fundamental. Brasília: D.F., 1997. Disponível em: http://portal.mec.gov.br/seb/arquivos/pdf/matematica.pdf. Acesso em: 5, maio 2019.

CIRÍACO, K. T. Professoras iniciantes e o aprender a ensinar Matemática em um grupo colaborativo. 2016. 334f. Tese (Doutorado em Educação) - Faculdade de Ciências eTecnologia da Universidade Estadual Paulista "Júlio de Mesquita Filho", FCT/UNESP, Presidente Prudente-SP. 2016. Disponível em: https://repositorio.unesp.br/ bitstream/handle/11449/139512/ciriaco_kt_dr_prud.pdf?sequence=3\&isAllowed=y. Acesso em: 15, fev. 2019.

CIRÍACO, K. T.; FAUSTINO, A. C.; ALMEIDA, C. R. M. F. de; SANTINO, F. S. Nas entrelinhas da pesquisa em Psicologia da Educação Matemática e a formação inicial de professores. Revista Eletrônica de Educação Matemática - REVEMAT, Florianópolis, v. 15, n. 1, p. 01-17, 2020. Disponível em: https://periodicos.ufsc.br/ index.php/revemat/article/view/19811322.2020.e65710/42699. Acesso em: 15, abr. 2020.

CIRÍACO, K. T.; PIROLA, N. A. "A Matemática, ela assusta um pouco": crença de autoeficácia e mudança de atitudes de estudantes de Pedagogia a partir da pesquisa na formação inicial. Revista Eletrônica de Educação Matemática, v. 13, n. 1, p. 147-162, 2018. Disponível em: https://periodicos.ufsc.br/index.php/revemat/article/ view/1981-1322.2018v13n1p147/37865 Acesso em: 1, mar. 2020.

CIRÍACO, K. T.; ZENERATI, F. R. Professoras da Educação Infantil e os princípios do cuidar/educar na prática docente. Revista Formação Docente. v. 7, n. 2 (2015). Disponível em: http://www3.izabelahendrix.edu.br/ojs/ index.php/fdc/article/view/791/703. Acesso em: 10, maio 2019.

CURI, E. Formação de professores polivalentes: uma análise de conhecimentos para ensinar Matemática e de crenças e atitudes que interferem na constituição desses conhecimentos. 2004. 278f. Tese (Doutorado em Educação Matemática) - Pontifícia Universidade Católica de São Paulo, PUC/SP. São Paulo-SP. 2004. Disponível em: http://www.educadores.diaadia.pr.gov.br/arquivos/File/2010/artigos_teses/MATEMATICA/ Tese_curi.pdf Acesso em: 25, mar. 2020.

CURI, E. PIRES. C.M.C. Pesquisas sobre a formação de professor que ensina matemática por grupos de pesquisa de instituições paulistanas. Educação Matemática Pesquisa. São Paulo, v. 10, n. 1, pp. 151-189, 2008. Disponível em: https://revistas.pucsp.br/emp/article/view/1655/1065. Acesso em: 30, mar. 2020. 
DUBAR, C. A socialização: construção das identidades sociais e profissionais. Tradução de Anette Pierrette R. Botelho e Estela Pinto R. Lamas. Portugal: Porto Editora, 1997.

FAUSTINO, A. C. "Como você chegou a esse resultado?": o diálogo nas aulas de Matemática dos anos iniciais do Ensino Fundamental. 2018. 232f. Tese (Doutorado em Educação Matemática) - Instituto de Geociências e Ciências Exatas de Rio Claro da Universidade Estadual Paulista "Júlio de Mesquita Filho". Rio ClaroSP. 2018. Disponível em: https://repositorio.unesp.br/bitstream/handle/11449/180358/faustino_ac_dr_rcla. pdf? sequence=3\&isAllowed=y. Acesso em: 30, set. 2019.

GAMA, R. P. Professores iniciantes e o desenvolvimento profissional: um olhar sobre as pesquisas acadêmicas brasileiras. In: FIORENTINI, D.; GRANDO, R. C.; MISKULIN, R. G. S. (Orgs.). Práticas de formação e de pesquisa de professores que ensinam Matemática. Campinas - SP: Mercado de Letras, 2009. p.101-124.

HUBERMAN, M. O ciclo de vida profissional dos professores. In: NÓVOA, A. (coord). Vidas de professores. Porto - Portugal: Porto editora, 1995. p.31-61.

KISHIMOTO, T. M. O jogo e a educação infantil. Perspectiva. Florianópolis, UFSC/CED, NUP, n. 22, p. 105-128. 1994. Disponível em: https://www.inesul.edu.br/professor/arquivos_alunos/doc_1311627204.pdf. Acesso em: 15 abr. 2019.

LÜDKE, M.; ANDRÉ, M. E.D.A. Pesquisa em educação: abordagens qualitativas. São Paulo: E.P.U, 1986.

MANZINI, E.J. Entrevista semi-estruturada: análise de objetivos e de roteiro. In: Seminário Internacional sobre Pesquisa e Estudos Qualitativos, 2, 2004, Bauru. A pesquisa qualitativa em debate. Anais...Bauru: USC, 2004. CD - ROOM. ISBN:85-98623-01-6.

MARCELO GARCÍA, C. Formação de professores: para uma mudança educativa. Tradução de Isabel Narciso. Porto, PT: Porto, 1999.

MIZUKAMI, M. da G. N. Aprendizagem da docência: professores formadores. Revista E-Curriculum, São Paulo, v. 1, n. 1, dez. - jul. 2005-2006. Disponível em: https://revistas.pucsp.br/curriculum/article/view/3106/2046 Acesso em: 02, mar. 2020.

NACARATO, A. M.; PASSOS, C. L. B. A Geometria nas séries iniciais: uma análise sob a perspectiva da prática pedagógica e da formação de professores. São Carlos: EdUSFCar. 2003.

NEVES, C. S. de V. Possíveis contribuições do estágio curricular supervisionado para a construção da identidade profissional de professor. 2011. 115f. Dissertação (Mestrado em Educação) - Faculdade de Educação da Universidade Federal de Pelotas, FE/UFPel. Pelotas-RS. 2011. Disponível em: http://bdtd.ibict.br/vufind/ Record/UFPL_e646c672062a538cc42ba75a19e2f5e9. Acesso em: 15, jan. 2020.

NÓVOA, A. Os professores e as histórias da sua vida. In: NÓVOA, A. (Org). Vidas de professores. Porto Ed. 2007. p.11-30.

OSTETTO, L. E; KOLB-BERNARDES. R. Modos de falar de si: a dimensão estética nas narrativas autobiográficas. Pro-Posições. V. 26 , n.1 (76) P.161 - 178. Jan./abr. 2015. Disponível em: http://www.scielo.br/pdf/pp/ v26n1/0103-7307-pp-26-01-0161.pdf. Acesso em: 12, ago. 2018. 
PASSOS, C. L. B; NACARATO, A. M. Trajetória e perspectivas para o ensino de Matemática nos anos iniciais. Estud. av. [online]. 2018, vol.32, n.94, pp.119-135. ISSN 0103-4014. Disponível em: http://www.scielo. br/pdf/ea/v32n94/0103-4014-ea-32-94-00119.pdf. Acesso em: 01, mar. 2019.

PEREIRA, C. C. M. O início de carreira de duas professoras dos anos iniciais do ensino fundamental e o ensino da matemática. Revista Paranaense de Educação Matemática. Campo Mourão, PR, v.4, n.6, p.177198, jan.-jun. 2015. Disponível em: http://www.fecilcam.br/rpem/documentos/v4n6/artigo_09.pdf. Acesso em: 03, nov. 2019.

ROCHA, G. A. Por uma política institucional comprometida com o início da carreira docente enquanto um projeto coletivo. In: 29a Reunião Anual da ANPED. Caxambu/MG, 2006. Disponível em: http://www.anped. org.br/sites/default/files/gt08-2611-int.pdf. Acesso em: 03, mar. 2020.

SANDER, G. P. Pró-Letramento: um estudo sobre a resolução de problemas e as atitudes em relação à Matemática apresentadas por professores do primeiro ciclo do Ensino Fundamental. 2014. 214f. Dissertação (Mestrado em Educação para Ciência) - Faculdade de Ciências, Universidade Estadual Paulista "Júlio de Mesquita Filho", FC/UNESP, Bauru-SP. 2014. Disponível em: https://repositorio.unesp.br/bitstream/handle/11449/154653/000898000.pdf? sequence=1\&isAllowed=y. Acesso em: 23, mar. 2019.

SANTINO, F. S. Identidade profissional de professores iniciantes: correlações entre a pesquisa em Educação Matemática e a constituição da prática pedagógica. 2018. 35f. Iniciação Científica (Licenciatura em Pedagogia) - Relatório de Pesquisa - Pró-Reitoria de Pesquisa e Pós-Graduação da Universidade Federal de Mato Grosso do Sul - UFMS. 2018.

SILVA, E. T. O ato de ler: fundamentos psicológicos para uma nova pedagogia da leitura. São Paulo, Cortez: Autores Associados. 1981.

SKOVSMOSE, O. Um convite à Educação Matemática crítica. Tradução de Orlando de Andrade Figueiredo. - Campinas, SP: Papirus, 2014.

SMOLE, K. C. S. A Matemática na Educação Infantil: a teoria das inteligências múltiplas na prática escolar. Porto Alegre, Editora Artes Médicas: 1996.

TARDIF, M. Saberes docentes e formação profissional. 5. ed. Petrópolis: Vozes, 2002.

VEENMAN, S. Problemas percebidos de professores iniciantes. Review of educational Research, v. 54, n.2. 1984, p. 39-68.

ZORTÊA, G. A. P. Conhecimentos "de" e "sobre" Geometria de duas professoras iniciantes no contexto de um grupo colaborativo. 2018. 152f. Dissertação (Mestrado em Ensino e Processos Formativos) - Faculdade de Engenharia de Ilha Solteira da Universidade Estadual Paulista "Júlio de Mesquita Filho," FEIS/UNESP. 2018. Disponível em: https://repositorio.unesp.br/bitstream/handle/11449/154335/zortea_gap_me_ilha. pdf? sequence=3\&isAllowed=y. Acesso em: 15, out. 2019.

SANTINO, F. S.; CIRÍACO, K. T.; FAUSTINO, A. C.; Percepções de uma professora iniciante acerca das contribuições da pesquisa em sua formação inicial para o ensino de matemática Formação Docente - Revista Brasileira de Pesquisa sobre Formação de Professores. Belo Horizonte. Vol. 13, nº 26 (p. 45-66) 30 abr. 2020. ISSN:2176-4360. DOI https://doi.org/10.31639/rbpfp.v13i26.359 
